NOTA CIENTÍFICA

\title{
AVALIAÇÃO DE FERTILIZANTES ORGÂNICOS NA PRODUÇÃO DE ALFACE EM CAMPO GRANDE, MS
}

\section{EVALUATION OF ORGANIC FERTILIZERS ON CROP LETTUCE IN CAMPO GRANDE, MS}

\author{
Antonia Railda ROEL ${ }^{1}$ \\ Liliane Aiko Kobaiashi LEONEL ${ }^{2}$ \\ Simone Palma FAVARO ${ }^{3}$ \\ Mariana ZATARIM ${ }^{4}$ \\ Cristiane Maria Vendramini MOMESSO ${ }^{5}$ \\ Maira Vicente SOARES ${ }^{6}$
}

\begin{abstract}
RESUMO
Objetivou-se investigar a eficiência de fertilizantes na cultura da alface em sistema orgânico, nas condições edafoclimáticas da região de Campo Grande, MS. As cultivares Verônica e Regina foram pulverizadas, aos 10 e 20 dias do transplante, com os fertilizantes orgânicos: Biofertilizante enriquecido (supermagro) a 1\% e 3\%, EM5 (produto comercial) a 0,1\%; Microgeo (produto comercial) 3\%, Extrato Pirolenhoso 0,2\% e testemunha. Constatou-se que os produtos testados como fertilizantes nas cvs Verônica e Regina, não alteraram os valores de massa fresca, massa seca (\%), teor de umidade nas cultivares avaliadas em relação à testemunha.
\end{abstract}

Palavras-chave: Lactuca sativa L.; agricultura sustentável; biofertilizantes.

\begin{abstract}
This work aimed to evaluate the efficiency fertilizers on lettuce crop grown with organic system at environmental local conditions. The cultivars Verônica and Regina were sprayed at 10 and 20 days after planting, with organic biofertilizers: 1 and $3 \%$ enriched biofertilizer (supermagro); $0,1 \% \mathrm{EM} 5 ; 3 \%$ Microgeo; $0,2 \%$ pirolenhoso extract, and control (lettuce without application of any product). Fresh weight, dry matter (\%) and moisture did not show difference among all treatments for the assayed cultivars.

Key-words: Lactuca sativa L.; sustainable agriculture; biofertilizes.
\end{abstract}

\footnotetext{
${ }^{1}$ Engenheira Agrônoma, Drạ . em Entomologia - Professora da Universidade Católica Dom Bosco/UCDB, Campo Grande(MS). Email:arroel@ucdb.br. Autor para correspondência

${ }^{2}$ Engenheira Agrônoma, MSc em Fitotecnia - Pesquisadora do IDATERRA, Dourados (MS).

${ }^{3}$ Engenheira Agrônoma, Dr ${ }^{\mathrm{a}}$. em Tecnologia de Alimentos - Professora da Universidade Católica Dom Bosco/UCDB, Campo Grande, MS

${ }^{4}$ Engenheira Agrônoma, MSc em Fitotecnia - Pesquisadora doIDATERRA, Campo Grande (MS)

${ }^{5}$ Nutricionista - Mestranda -Desenvolvimento Local - Universidade Católica Dom Bosco/UCDB, Campo Grande (MS).

${ }^{6}$ Acadêmica do Curso de Agronomia - Universidade Católica Dom Bosco, Campo Grande(MS)
} 
ROEL, A.L. et al. Avaliação de fertilizantes orgânicos...

\section{INTRODUÇÃO}

A alface Lactuca sativa L. é cultura de clima temperado melhor adaptada a temperaturas baixas, com a máxima tolerada em torno de $30^{\circ} \mathrm{C}$ e a mínima em torno de $6{ }^{\circ} \mathrm{C}$, para a maioria das cultivares (CERMEÑO, 1990). Apesar de ser olerícola de fácil cultivo, é dependente de insumos químicos, como fertilizantes e de produtos para o controle fitossanitário, especialmente em condições de altas temperaturas e umidade, que favorecem ao ataque de pragas e doenças.

No entanto, a utilização de insumos agrícolas, adubos sintéticos e biocidas contaminam o agroecossistema, aumentam os custos de produção e quando não bem manejados intoxicam o agricultor. O cultivo no sistema orgânico, com a utilização de defensivos alternativos para o controle fitossanitário, produz alimento mais saudável, sem resíduos químicos, preservando o meio ambiente e melhorando a qualidade de vida do homem (MEIRELLES, 1997).

Materiais orgânicos adicionados ao solo na forma de adubos orgânicos, de acordo com o grau de decomposição dos resíduos, podem ter efeito imediato no solo, ou efeito residual, por meio de um processo mais lento de decomposição e disponibilidade de nutrientes às plantas na medida da necessidade, que proporciona maiores condições de resistir às agressões (CHABOUSSOU, 1987; PRIMAVESI, 1990; GLIESSMAN, 2001).

A adubação orgânica além de apresentar grande efeito residual, presta-se ainda à reciclagem de resíduos rurais, o que possibilita maior autonomia dos produtores em face do comércio de insumos (SANTOS et al., 2001). Constataram ainda um aumento linear dos teores de bases trocáveis, de fósforo $(P)$ e da capacidade efetiva de troca de cátions, (CTC) do solo em experimento com efeito residual doses crescentes de composto orgânico.

Para a prática da agricultura orgânica não é permitido o uso de produtos sintéticos, adubos minerais e biocidas. Para a fertilização e proteção das plantas, a prática aceita o uso de produtos naturais, biofertilizantes e alguns produtos comerciais. No entanto, GONÇALVES et al. (2004) concluíram que biofertilizantes anaeróbico (50\%) e aeróbico $(5 \%)$ e extratos vegetais em cinco pulverizações em cebola não incrementaram a produtividade e massa fresca de bulbos ou causaram redução na incidência de tripes. Entretanto, as recomendações sobre esses fertilizantes naturais suas aplicações e dosagens são feitas sem comprovação sobre a eficiência.

Segundo MAGRO (1994), biofertilizantes são compostos bioativos, resíduo final da fermentação de compostos orgânicos, contendo células vivas ou latentes de microorganismos (bactérias, leveduras, algas e fungos filamentosos) e por seus metabólitos, além de quelatos organominerais. São produzidos em biodigestores por meio de fermentação aeróbica e/ou anaeróbica de material orgânico. Esse composto é descrito como rico em enzimas, antibióticos, vitaminas, toxinas, fenóis, ésteres e ácidos de ação hormonal.
O Microgeo é um produto que contém preparados biodinâmicos elaborados a partir de plantas medicinais (milfolhas, camomila, urtiga, casca-de-carvalho, dente-de-leão e valeriana) que organizam os processos de fermentação do composto e dos biofertilizantes e é recomendado com a finalidade de nutrir as plantas cultivadas (D‘ANDREA, 2003).

O extrato pirolenhoso é o líquido obtido da condensação da fumaça no processo de carbonização da madeira, constituído de 200 componentes químicos diferentes, em especial o ácido acético, metanol e acetona, diluído em água melhora as propriedades físicas, químicas e biológicas do solo (MIYASAKA et al., 2001).

O produto biofertilizante EM5 é um preparado a base de solução fermentada de vinagre, álcool, melaço e EM (Microrganismos Eficazes) é indicado para utilização via foliar como preventivo contra pragas e doenças. É um líquido que contém vários grupos de microrganismos, dentre os quais podemos citar bactérias produtoras de ácido láctico, leveduras, actinomicetos, fungos filamentosos e bactérias fotossintéticas que, através de mecanismo especial, em um mesmo meio líquido (FUNDAÇÃO MOKITI OKADA, 1998).

Objetivou-se assim, conhecer os efeitos dos produtos recomendados como fertilizantes naturais para suprir as carências nutricionais e proteger de agentes patogênicos, em duas cultivares de alface, cultivadas com fertilizantes orgânicos.

\section{MATERIAL E MÉTODOS}

O experimento foi desenvolvido no CEPACI/ IDATERRA em Campo Grande (MS), altitude 480 metros, latitude 20 $38^{\prime} 47^{\prime \prime}$ e longitude 54 $38^{\prime} 47^{\prime \prime}$. O solo é tipo Neossolo e o clima tipo tropical úmido, caracterizado por uma estação seca acentuada no inverno e chuvosa no verão. Sua temperatura média anual é de $23^{\circ} \mathrm{C}$, sendo que na ocasião do plantio, época seca, as temperaturas eram mais amenas, com média mensal de $25,32^{\circ} \mathrm{C}$ (min. $20,54{ }^{\circ} \mathrm{C}$ e máx. $32,16{ }^{\circ} \mathrm{C}$ ) e precipitação acumulada de $57,90 \mathrm{~mm}$. O sistema de irrigação adotado foi aspersão, duas vezes ao dia.

As cultivares estudadas Verônica (tipo crespa) e Regina (tipo lisa) foram semeadas em bandejas de polietileno com substrato Plantmax em 01/02/2004, mantidas em casa telada e irrigadas diariamente. $O$ transplante para o campo, em regime de céu aberto, foi efetuado em 04/03/2004.

$A$ adubação de plantio foi com composto orgânico, a base de palhada de soja, feijão e milho acrescido de esterco de galinha na proporção de 3:1 (origem vegetal e animal), incorporado no solo uma semana antes do transplante na dosagem de $4 \mathrm{~kg}$ $\mathrm{m}^{-2}$, ou seja, $40.000 \mathrm{~kg} \mathrm{ha}^{-1}$. Adicionado de fosfato como termofosfato (Yoorin master) calculado para 1 $t \mathrm{th}^{-1}$ e micronutrientes $(0,10 \%$ de $\mathrm{B}, 0,55 \%$ de $\mathrm{Zn}$, 30,0 $\mathrm{Mg} \mathrm{ha}^{-1}$ ).

O composto orgânico utilizado na área do experimento foi fermentado e aplicado na dosagem e época correta como recomendado por SCHNEIDER (1983), que é de 10 a $100 \mathrm{t} \mathrm{ha}^{-1}$ dependendo tipo do 
ROEL, A.R. et al. Avaliação de fertilizantes orgânicos...

composto, do solo, da cultura e das condições ambientais. A análise de solo da área experimental foi feita no Laboratório de Solos e Nutrição de Plantas da Universidade Católica Dom Bosco - UCDB (Tabela 1).

O delineamento experimental foi em blocos ao acaso, com quatro repetições. Cada parcela de $2 \mathrm{~m}^{2}$, continha 4 linhas de 2 metros, no espaçamento de $0,25 \mathrm{~cm}$ entre plantas e entre linhas, ou seja, 32 plantas por parcela. As avaliações foram efetuadas em quatro plantas da área útil, na parte central por parcela, transformadas em média por cabeça. As médias dos tratamentos foram comparadas pelo Teste de Tukey a 5\% de probabilidade.

TABELA 1 - Análise química do solo da área experimental. Campo Grande, MS, 2004

\begin{tabular}{|c|c|c|c|c|c|c|c|c|c|c|c|}
\hline Prof. & \multicolumn{2}{|c|}{$\mathrm{pH}$} & M.O. & $\mathrm{P}$ & K & $\mathrm{Ca}$ & $\mathrm{Mg}$ & $\mathrm{Al}$ & $\mathrm{H}+\mathrm{Al}$ & CTC & V \\
\hline (cm) & $\mathrm{CaCl}_{2}$ & $\mathrm{H}_{2} \mathrm{O}$ & $\mathrm{g} \mathrm{kg}^{-1}$ & $\mathrm{mg} \mathrm{dm}^{-3}$ & & & & $\left.n^{-3}\right)$ & & & (\%) \\
\hline $0-20$ & 6,91 & 6,12 & 34,3 & 261,6 & 0,22 & 5,3 & 5,0 & 0,0 & 3,1 & 13,6 & 77,5 \\
\hline
\end{tabular}

Foram avaliados, seis tratamentos em pulverizações foliares, de $200 \mathrm{ml}$ por parcela, em aplicações efetuadas aos 10 e 20 dias do transplante: Biofertilizante enriquecido (supermagro) a $1 \%$ e $3 \%$, Microrganismos Eficazes, EM5 (produto comercial) a $0,1 \%$; Microgeo (produto comercial) $3 \%$; Extrato Pirolenhoso $0,2 \%$ e testemunha (pulverizadas com água). Em todas as caldas foram adicionadas de melaço de cana-de-açúcar como espalhante adesivo.

A colheita foi realizada em 04/05/2004, cortando-se o caule rente ao solo. Imediatamente após, as quatro plantas da área útil foram avaliadas quanto à porcentagem de massa fresca e diâmetro da cabeça. Após essas avaliações as plantas foram embaladas em sacos de papel e levadas ao laboratório de Fitossanidade da UCDB para avaliação da porcentagem de massa seca e teor de umidade. A umidade foi determinada em estufa a $105^{\circ} \mathrm{C}$ até peso constante e expressa em percentagem.

As avaliações fitossanitárias foram efetuadas durante todo o período da cultura, duas vezes por semana, por meio de observação visual, em todas as plantas da área útil, com auxílio de lupa com aumento de quatro vezes, para identificar a ocorrência de pragas e doenças, nos diferentes tratamentos.

\section{RESULTADOS E DISCUSSÃO}

Não foram observadas doenças ou pragas em qualquer tratamento, fato que pode ser explicado pela época de condução do experimento, quando a maioria das espécies de insetos ocorre em infestações menores. A não ocorrência de problemas sanitários pode ser explicada por CHABOUSSOU (1987) que afirma que o aparecimento de pragas na agricultura, ou seja, a susceptibilidade da planta a insetos está ligada a fatores como a adubação mineral e o uso de pesticidas e relacionados ao equilíbrio entre a síntese e decomposição de proteínas no processo de crescimento vegetal. Também PRIMAVESI (1990) acrescenta que, quando aparecem pragas, é porque o meio ambiente do solo lhes é favorável.

A umidade variou entre 90 e $94 \%$ e não se observou diferenças entre os tratamentos entre as duas cultivares em relação à testemunha. Valores semelhantes foram constatados por VILLAS BÔAS et al. (2004) em cultivares de alface com adubações orgânicas.

\section{Cultivar Verônica}

Para a cultivar Verônica (Tabela 2) não se observou diferenças significativas entre os tratamentos (Microgeo, Biofertilizante 1\%, Biofertilizante 3\%, EM5 e Extrato pirolenhoso) com os valores médios por cabeça de 158,58 a 124,94 g em relação à testemunha $(114,04 \mathrm{~g})$. Valores semelhantes de peso médio por cabeça foram obtidos também por ZAGONEL et al. (2002) para a mesma cultivar. 
ROEL, A.L. et al. Avaliação de fertilizantes orgânicos...

TABELA 2 - Peso fresco, peso seco, massa seca e diâmetro da cabeça da A) alface crespa cv Verônica e B) alface lisa cv Regina, conduzidas em sistema orgânico a céu aberto pulverizadas com fertilizantes. Campo Grande, MS, 2004.

\begin{tabular}{|c|c|c|c|c|}
\hline Tratamento & $\begin{array}{c}\text { Massa fresca }{ }^{(1)} \\
(\mathrm{g})\end{array}$ & $\begin{array}{c}\text { Peso Seco } \\
\text { (g) }\end{array}$ & $\begin{array}{c}\text { Massa seca } \\
\%\end{array}$ & $\begin{array}{c}\text { Diâmetro da } \\
\text { Cabeça } \\
(\mathrm{cm})\end{array}$ \\
\hline \multicolumn{5}{|c|}{ A) alface crespa cv Verônica } \\
\hline Microgeo & $158,58 a^{(2)}$ & $9,82 \mathrm{a}$ & $6,13 \mathrm{a}$ & $22,37 \mathrm{a}$ \\
\hline Biofertilizante $1 \%$ & $124,94 \mathrm{a}$ & $7,22 \mathrm{a}$ & $5,77 \mathrm{a}$ & 20,69 a \\
\hline Biofertilizante 3\% & $132,24 \mathrm{a}$ & $6,74 \mathrm{a}$ & $5,23 \mathrm{a}$ & $20,00 \mathrm{a}$ \\
\hline EM5 & $129,85 \mathrm{a}$ & $7,42 \mathrm{a}$ & $9,53 \mathrm{a}$ & $22,25 \mathrm{a}$ \\
\hline Extrato Pirolenhoso & $127,53 \mathrm{a}$ & $7,48 \mathrm{a}$ & 5,89 a & $23,25 \mathrm{a}$ \\
\hline Testemunha & $114,04 \mathrm{a}$ & $6,45 \mathrm{a}$ & $5,72 \mathrm{a}$ & $19,69 \mathrm{a}$ \\
\hline C.V.\% & 13,79 & 12,41 & 17,34 & 9,40 \\
\hline
\end{tabular}

B) alface lisa cv Regina

\begin{tabular}{|c|c|c|c|c|}
\hline Microgeo & $136,12 a^{(2)}$ & $8,13 \mathrm{a}$ & $5,96 \mathrm{a}$ & $19,50 \mathrm{a}$ \\
\hline Biofertilizante $1 \%$ & $116,63 \mathrm{a}$ & $6,92 \mathrm{a}$ & $5,94 \mathrm{a}$ & $17,75 \mathrm{a}$ \\
\hline Biofertilizante 3\% & $120,08 \mathrm{a}$ & $6,43 a$ & $5,26 \mathrm{a}$ & $17,25 \mathrm{a}$ \\
\hline EM5 & $107,14 \mathrm{a}$ & $6,01 \mathrm{a}$ & $5,64 a$ & $17,25 \mathrm{a}$ \\
\hline Extrato Pirolenhoso & $123,53 \mathrm{a}$ & $7,43 \mathrm{a}$ & $6,01 \mathrm{a}$ & $16,50 \mathrm{a}$ \\
\hline Testemunha & $130,44 a$ & $7,27 \mathrm{a}$ & $5,56 \mathrm{a}$ & $20,75 a$ \\
\hline C.V. & 13,79 & 13,75 & 17,98 & 12,02 \\
\hline
\end{tabular}

(1) peso médio por unidade

${ }^{(2)}$ médias seguidas da mesma letra não diferem entre si pelo teste de Tukey a $5 \%$ de probabilidade.

Também não se observou diferenças significativas para o peso seco, entre os tratamentos 6,74 a $9,82 \mathrm{~g}$ e a testemunha $6,45 \mathrm{~g}$. Assim como para a porcentagem de massa seca, onde os valores observados para os tratamentos variaram entre 5,23 a $9,53 \%$ em relação à testemunha 5,72\%. Também o diâmetro da cabeça todos os valores se mostraram iguais em relação à testemunha, $19,69 \mathrm{~g}$ para a testemunha e entre 20 a 23,25 g entre os tratamentos. Estes dados evidenciam que os tratamentos não influenciaram no acúmulo de matéria orgânica e inorgânica, sendo este proporcional a de massa de material fresco das cabeças de alface.

\section{Cultivar Regina}

Diferenças significativas não foram observadas (Tabela 2) entre os pesos médios da alface cv Regina, entre os tratamentos Microgeo, Biofertilizante 1\%, Biofertilizante 3\%, EM5 e Extrato pirolenhoso, 136,12; 116,63; 120,08; 107,14; 123,53 $\mathrm{g}$, respectivamente, e em relação à testemunha 130,44g. VILLAS BÔAS et al. (2004), em avaliação 
ROEL, A.R. et al. Avaliação de fertilizantes orgânicos...

sobre o efeito de tipos de compostos orgânicos na produção de alface cv. Elisa, relataram valores semelhantes quando as plantas foram cultivadas com compostagem a base de plantas de feijão.

Não se observou diferença entre os tratamentos para o peso seco $(6,01$ a $8,13 \mathrm{~g})$ em relação à testemunha $7,27 \mathrm{~g}$. Da mesma maneira para a porcentagem de massa seca os valores observados entre os tratamentos, 5,26 a $6,01 \%$ não diferiram entre si ou em relação à testemunha $(5,56 \%)$. Todos os valores considerados estatisticamente iguais também para o diâmetro da cabeça $(16,5$ a $19,5 \mathrm{~cm})$ em relação à testemunha $(20,75 \mathrm{~cm})$

Sabe-se que a adubação orgânica tem efeitos muito conhecidos nas propriedades físicas, químicas e biológicas do solo, importante para o cultivo de hortaliças em solos do cerrado (SWIFT e WOOMER, 1993; PRIMAVESI, 1990). Adicionado ao solo tem efeito imediato e residual por processo mais lento de decomposição e liberação de nutrientes.

A fertilidade do solo e a adubação utilizada podem explicar a falta de resposta dos biofertilizantes testados, ou seja, as plantas podem ter alcançado um bom desempenho em presença de níveis satisfatórios de nutrientes, que foram liberados continuamente durante o ciclo da cultura. Ou seja, os nutrientes presentes no solo, no $\mathrm{pH}$ observado, supriram as necessidades da planta (Quadro 1).

GONÇALVES et al. (2004), consideraram que como o objetivo da maioria das substâncias alternativas utilizadas em sistemas agroecológicos é promover o equilíbrio nutricional das plantas, seria interessante realizar trabalhos com análise da qualidade nutricional do alimento, assim como a conservação pós-colheita, pois a qualidade fisiológica do alimento produzido pode estar sendo alterada, sem incremento na produtividade.

\section{CONCLUSÃO}

Os produtos fertilizantes avaliados, Microgeo, Biofertilizante, EM5, Extrato pirolenhoso, em alface cultivada com adubação orgânica, não apresentaram resposta quanto aos valores de massa fresca, porcentagem de massa seca, teor de umidade nas cultivares Regina e Verônica no município de Campo Grande, MS, cultivadas a céu aberto, de março abril de 2004.

\section{REFERÊNCIAS}

1. CERMEÑO, Z.S. Estufas: instalações e manejo. Lisboa: Litexa Editora, 1990. 355 p.

2. CHABOUSSOU, F. Plantas doentes pelo uso de agrotóxicos: a teoria da trofobiose. Porto Alegre: L \& PM, 1987. $272 \mathrm{p}$.

3. D'ANDREA, P. Agricultura de processos. In: SIXEL, B.T. Biodinâmica e agricultura. Botucatu: Associação Brasileira de Agricultura Biodinâmica, 2003. p. 155-181.

4. FUNDAÇÃO MOKITI OKADA. Microrganismos eficazes na agricultura. São Paulo: Centro de Pesquisa - Ipeúna, 1998.

5. GLIESSMAN, S.R. Agroecologia: processos ecológicos em agricultura sustentável. 2.ed. Porto Alegre: UFRGS, 2001. 653 p.

6. GONÇALVES, P.A.S.; WERNER, H.; DEBARBA, J.F. Avaliação de biofertilizantes, extratos vegetais e diferentes substâncias alternativas no manejo de tripes em cebola em sistema orgânico. Horticultura Brasileira, v. 22, n. 3, 2004

7. MAGRO, D. Supermagro: a receita completa. Boletim da Associação de Agricultura Orgânica, n. 16, p. 3-4, 1994

8. MEIRELLES, L. Produção e comercialização de Hortaliças orgânicas. Horticultura Brasileira, v. 1, n. 1, p. 205-210, 1997. (suplemento)

9. MIYASAKA, S.; OHKAWARA, T.; NAGAI, K.; YAZAKI, H.; SAKITA, M.N. Técnicas de produção e uso do Fino de Carvão e Licor Pirolenhoso In: ENCONTRO DE PROCESSOS DE PROTEÇÃO DE PLANTAS: Controle ecológico de pragas e doenças, 1., 2001, Botucatu. Resumos. p.161-176.

10. PRIMAVESI, A. M. Manejo ecológico dos solos. 9. ed. São Paulo: Nobel, 1990. 514 p.

11. SANTOS, R.H.S.; SILVA, F. da; CASELI, V.W.D.; CONDE, A.R. Efeito residual da adubação com composto orgânico sobre o crescimento e produção de alface. Pesquisa Agropecuária Brasileira, v. 36, n. 11, p. 1395-1398, 2001

12. SCHNEIDER, L. Rendimento e qualidade de alface em função da adubação nitrogenada, orgânica e mineral. Porto Alegre, 1983. 69 f. Dissertação (Mestrado em Agronomia) - Curso de Pós Graduação em Agronomia, Faculdade de Agronomia, Universidade Federal do Rio Grande do Sul.

13. SWIFT, M.J.; WOOMER, P. Organic matter and the sustainability of agricultural systems: definitions and measurement. In: MULUNGOY, K.; MERCKX, R. (Eds.). Soil organic matter dynamics sustainability of tropical agriculture. Leuven: WileiSayce, 1993. p. 3-18.

14. VILLAS BÔAS, R.L.; PASSOS, J.C.; FERNANDESM D.M.; BÜLL, L.T.; CÉZAR, V.R.; GOTO, R. Efeito de doses e tipos de compostos orgânicos na produção de alface em dois solos sob ambiente protegido. Horticultura Brasileira, v. 22, n. 1, p. 2834, 2004

15. ZAGONEL, J.; REGUIM, M.Y.; PRIA, M.D.; KUNZ, R.P. Avaliação de inseticidas no controle de Myzus persicae (Sulz.) (Homoptera: Aphididae) na cultura da alface. Horticultura Brasileira, v. 20, n. 3, p. 514-515, 2002.

Recebido em 22/12/2006 Aceito em 20/07/2007 
